Short Communication

\title{
In vitro activity of ceftolozane-tazobactam against Enterobacterales and Pseudomonas aeruginosa causing urinary, intra-abdominal and lower respiratory tract infections in intensive care units in Portugal: The STEP multicenter study
}

\author{
Sergio García-Fernández ${ }^{\mathrm{a}, \mathrm{b}}$, María García-Castillo ${ }^{\mathrm{a}, \mathrm{b}}$, José Melo-Cristinoc, \\ Margarida F. Pinto ${ }^{d}$, Elsa Gonçalves ${ }^{e}$, Valquíria Alves ${ }^{\mathrm{f}}$, Ana Raquel Vieira ${ }^{\mathrm{g}}$, \\ Elmano Ramalheira ${ }^{\mathrm{h}}$, Luísa Sancho ${ }^{i}$, José Diogo ${ }^{\mathrm{j}}$, Rui Ferreirak ${ }^{\mathrm{k}}$, Daniela Silva ${ }^{\mathrm{l}}$, \\ Catarina Chaves $^{\mathrm{m}}$, Leonor Pássaro ${ }^{\mathrm{n}}$, Laura Paixão ${ }^{\mathrm{n}}$, Rafael Cantón ${ }^{\mathrm{a}, \mathrm{b}, *}$, on behalf of the \\ STEP Study Group
}

\footnotetext{
a Servicio de Microbiología, Hospital Universitario Ramón y Cajal and Instituto Ramón y Cajal de Investigación Sanitaria (IRYCIS), Madrid, Spain

${ }^{\mathrm{b}}$ Red Española de Investigación en Patología Infecciosa (REIPI), Madrid, Spain

' Serviço de Microbiologia Centro Hospitalar Lisboa Norte, Lisboa, Portugal

${ }^{\mathrm{d}}$ Laboratório de Microbiologia, Serviço de Patologia Clínica, Centro Hospitalar Universitário Lisboa Central, Lisboa, Portugal

e Laboratório de Microbiologia Clínica Centro Hospitalar de Lisboa Ocidental, Lisboa, Portugal

${ }^{\mathrm{f}}$ Serviço de Microbiologia, Unidade Local de Saúde de Matosinhos, Matosinhos, Portugal

Serviço Patologia Clínica, Centro Hospitalar Universitário São João, Porto, Portugal

h Serviço Patologia Clínica, Hospital Infante Dom Pedro, Aveiro, Portugal

i Serviço de Patologia Clínica, Hospital Prof. Dr. Fernando da Fonseca, Amadora, Portugal

j Serviço de Microbiologia, Hospital Garcia de Orta, Alnada, Portugal

${ }^{k}$ Serviço de Patologia Clínica - Microbiologia - CHUA - Unidade de Portimão, Portimão, Portugal

${ }^{1}$ Serviço de Microbiologia do Centro Hospitalar Universitário do Porto, Porto, Portugal

${ }^{\mathrm{m}}$ Serviço de Microbiologia, Centro Hospitalar Universitário de Coimbra, Coimbra, Portugal

${ }^{\mathrm{n}}$ MSD Portugal, Paço de Arcos, Portugal
}

\section{A R T I C L E I N F O}

\section{Article history:}

Received 2 October 2019

Accepted 28 December 2019

Editor: Professor A Tsakris

\section{Key words:}

Ceftolozane-tazobactam

Intensive care unit

Portugal

Intra-abdominal infection

Urinary tract infection

Lower respiratory tract infection

\begin{abstract}
A B S T R A C T
The STEP surveillance study was designed to increase knowledge about distribution of multidrug-resistant (MDR) Enterobacterales and Pseudomonas aeruginosa in Portugal, focusing on the intensive care unit (ICU). Antimicrobial susceptibility of common agents was also evaluated and compared with that of one of the latest therapeutic introductions, ceftolozane-tazobactam $(\mathrm{C} / \mathrm{T})$. Clinical isolates of Enterobacterales $(\mathrm{n}=426)$ and $P$. aeruginosa $(\mathrm{n}=396)$ from patients admitted in Portuguese ICUs were included. Activity of $\mathrm{C} / \mathrm{T}$ and comparators was investigated using standard broth microdilution. Isolates were recovered from urinary tract (UTI, 36.9\%), intra-abdominal (IAI, 24.2\%) and lower respiratory tract (LRTI, 38.9\%) infections. In P. aeruginosa, overall distribution of MDR/extremely-drug resistant (XDR)/pan-drug resistant (PDR) isolates accounted for $21.2 \%, 23.2 \%$ and $0.8 \%$, respectively. C/T was the most potent agent tested against $P$. aeruginosa and MDR/XDR/PDR phenotypes. In Escherichia coli, extended-spectrum beta-lactamases (ESBL) and carbapenemase (CP) phenotypes accounted for $16.6 \%$ and $1.7 \%$, respectively, whereas in Klebsiella spp., ESBL and CP-phenotypes represented $28.5 \%$ and $17.9 \%$, respectively. Overall, susceptibility of C/T against Enterobacterales was $86.9 \%$. C/T was the least affected agent in E. coli (99.4\% susceptibility), whereas its activity was moderate in Klebsiella spp. (71.5\%) and Enterobacter spp. (70.4\%), due in part to a high rate of ESBL and CP-phenotypes. In Enterobacterales, bla $a_{\mathrm{KPC}}$ was the most prevalent CP gene (63.0\%), followed by bla $_{\mathrm{OXA}-48}(33.3 \%)$ and bla $_{\mathrm{VIM}}(3.7 \%)$. These microbiological results reinforce $\mathrm{C} / \mathrm{T}$ as a therapeutic option in ICU patients with UTI, IAI or LRTI due to P. aeruginosa or Enterobacterales isolates, but not for CP producers.
\end{abstract}

(C) 2020 Elsevier B.V. and International Society of Chemotherapy. All rights reserved.

\footnotetext{
* Corresponding author: Rafael Cantón, Servicio de Microbiología, Hospital Universitario Ramón y Cajal. Ctra. Colmenar Km 9,1. 28034-Madrid. Spain.

E-mail address: rafael.canton@salud.madrid.org (R. Cantón).
} 


\section{Introduction}

Public health authorities have highlighted an increasing worldwide prevalence of antimicrobial resistance. This increase has been demonstrated in surveillance studies, particularly in Gram-negatives included in the so-called ESKAPE (Enterococcus faecium, Staphylococcus aureus, Klebsiella pneumoniae, Acinetobacter baumannii, Pseudomonas aeruginosa, and Enterobacter spp.) microorganisms [1,2]. Moreover, in Europe, the European Centre for Disease Prevention and Control (ECDC) has shown that antimicrobial resistance remains a serious threat, and is more important in the Mediterranean area than in Northern countries [3]. In Portugal, there are scarce data on antimicrobial surveillance, activity of antimicrobials and molecular epidemiology of resistance mechanisms. In invasive isolates recovered in Portugal in 2017, resistance to third-generation cephalosporins in Escherichia coli and K. pneumoniae accounted for $15.6 \%$ and $44.9 \%$, respectively [3]. Resistance to carbapenems increased in $E$. coli from $<0.1 \%$ to $0.3 \%$, and in $K$. pneumoniae from $1.8 \%$ to $8.6 \%$ during the period 2014 to 2017 [3], and the predominant carbapenemase (CP) in Portugal was the $b l a_{\mathrm{KPC}}[4,5]$. In $P$. aeruginosa isolates, resistance rates to piperacillin-tazobactam, ceftazidime and carbapenems were $24.2 \%$, $18.6 \%$ and $18.3 \%$, respectively [3]. There is even less information on high-risk areas for resistance, such as intensive care units (ICUs).

New $\beta$-lactam- $\beta$-lactamase inhibitors combinations have recently been developed to mitigate the effects of multidrugresistant (MDR) organisms [6-8]. Ceftolozane-tazobactam (C/T) was initially approved by the Food and Drug Administration (FDA) and European Medicines Agency (EMA) for complicated urinary tract infections (cUTI) and complicated intra-abdominal infections (cIAI). This combination has also been recently approved by the FDA for hospital-acquired and ventilator-associated bacterial pneumonia [9]. In the STEP (S usceptibility Testing on Enterobacterales and Pseudomonas aeruginosa) study, the in vitro activity of C/T and comparators was assessed against Enterobacterales and P. aeruginosa clinical isolates prospectively collected from ICU patients with UTI, IAI, and lower respiratory tract infections (LRTI) in Portugal.

\section{Material and Methods}

\subsection{Study design and setting}

A prospective, multicenter study was designed to assess the in vitro activity of $\mathrm{C} / \mathrm{T}$ and comparator antimicrobials against clinical isolates of Enterobacterales and $P$. aeruginosa prospectively recovered in Portuguese ICUs (June 2017-July 2018). Eleven Portuguese hospitals participated in the study (Fig. S1). University Hospital Ramón y Cajal in Madrid (Spain) acted as coordinator laboratory (hereafter central laboratory). Species identification was performed at each participant site and confirmed at the central laboratory using MALDI-TOF (Bruker-Daltonics, Bremen, Germany). The ethics committees of all participating sites in Portugal approved the study.

\subsection{Antimicrobial susceptibility testing}

Minimum inhibitory concentrations (MICs) were determined at the central laboratory using the standard broth microdilution method (BMD) using frozen 96-well plates (Thermo Fisher Scientific, Cleveland, $\mathrm{OH}$ ) [10]. The antimicrobials tested were: amikacin (AMK), amoxicillin-clavulanic acid (AMC), aztreonam, cefepime (FEP), cefotaxime (CTX), ceftazidime (CAZ), C/T, ciprofloxacin (CIP), colistin (CST), fosfomycin, gentamicin, imipenem (IPM), meropenem (MEM), piperacillin-tazobactam (TZP), tigecycline (TGC) and tobramycin. E. coli ATCC25922, E. coli ATCC35218, K. pneumoniae ATCC700603 and P. aeruginosa ATCC27853 were used as quality control. Interpretation of results and quality control were performed in accordance with European Committee on Antibiotic Susceptibility Testing (EUCAST) and Clinical and Laboratory Standards Institute (CLSI) guidelines [11,12]. For comparison purposes, the definition of susceptible (S) [susceptible plus susceptible, increased exposure (I), formerly intermediate for EUCAST] was applied to both EUCAST and CLSI. Moreover, resistant (R) clinical category was considered for phenotype definition. C/T breakpoints used were the following: [Enterobacterales, EUCAST (S, $\leq 2 / 4 \mathrm{mg} / \mathrm{L}$; $\mathrm{R},>2 / 4 \mathrm{mg} / \mathrm{L}$ ) and CLSI (S, $\leq 2 / 4 \mathrm{mg} / \mathrm{L} ; \mathrm{I}, 4 / 4 \mathrm{mg} / \mathrm{L} ; \mathrm{R}, \geq 8 / 4 \mathrm{mg} / \mathrm{L})$; P. aeruginosa, EUCAST (,$\leq 4 / 4 \mathrm{mg} / \mathrm{L} ; \mathrm{R},>4 / 4 \mathrm{mg} / \mathrm{L}$ ) and CLSI (S, $\leq 4 / 4 \mathrm{mg} / \mathrm{L} ; \mathrm{I}, 8 / 4 \mathrm{mg} / \mathrm{L} ; \mathrm{R}, \geq 16 / 4 \mathrm{mg} / \mathrm{L})]$.

\subsection{Phenotypic classification of isolates}

To evaluate the activity of $\mathrm{C} / \mathrm{T}$ against Enterobacterales, the following phenotypes were defined according to susceptibility to $\beta$ lactam antibiotics: 1 ) Extended-spectrum $\beta$-lactamase (ESBL) phenotype and 2) CP-phenotype. All isolates were evaluated according to CLSI and EUCAST screening criteria for suspected ESBL (MICs $\geq 2$ $\mathrm{mg} / \mathrm{L}$ for CTX, CAZ and/or FEP) producers [12]. Phenotypic confirmation of ESBL production was performed using the double-disk synergy (DDS) test. Suspected CP isolates displaying MICs of $>1$ $\mathrm{mg} / \mathrm{L}$ for IPM and/or $>0.12 \mathrm{mg} / \mathrm{L}$ for MEM were evaluated [12,13]. Phenotypic confirmation of CP production was performed using the ROSCO KPC/MBL and OXA-48 Confirm Kit (Rosco Diagnostica A/S, Taastrup, Denmark) following manufacturer instructions.

In $P$. aeruginosa isolates, the following resistant phenotypes were also defined using EUCAST interpretative criteria: 1) TZP-CAZR: combined TZP and CAZ non-susceptibility; 2) TZP-CAZ-MERR: combined TZP, CAZ and MER non-susceptibility; 3) MDR: nonsusceptibility to at least one agent in three or more antimicrobial categories; 4) Extensively drug-resistant (XDR): non-susceptibility to at least one agent in all but two or fewer antimicrobial categories; and 5) Pan-drug-resistant (PDR): non-susceptibility to all antimicrobials tested (except C/T) [14].

\subsection{Molecular characterization}

bla $_{\mathrm{ESBL}}$ and bla $_{\text {carbapenemase }}$ genes in Enterobacterales isolates with ESBL or CP-phenotype were characterized as previously described [15]. In $P$. aeruginosa isolates resistant to a C/T, CP genes were investigated using Cepheid Xpert ${ }^{\circledR}$ Carba-R assay (Cepheid, Sunnyvale, CA, USA).

\section{Results}

\subsection{Bacterial isolates}

A total of 822 clinical isolates of Enterobacterales $(n=426)$ and P. aeruginosa $(\mathrm{n}=396)$ were collected from June 2017 to July 2018 from patients admitted in Portuguese ICUs. Isolates were recovered from UTI $(n=303,36.9 \%)$, IAI $(n=199,24.2 \%)$ and LRTI $(n=320$, $38.9 \%$ ). Only one isolate per patient was included. Distribution of isolates by species and infection type is shown in Table S1.

\subsection{Antimicrobial susceptibility of Enterobacterales isolates}

Among E. coli isolates, $16.6 \%$ had a positive DDS test expressing an ESBL-phenotype $(\mathrm{n}=29), 1.7 \%$ a CP-phenotype $(\mathrm{n}=3)$ and $81.7 \%$ $(n=143)$ were non-ESBL-CP. In Klebsiella spp. isolates, $28.5 \%$ had a positive DDS test expressing an ESBL-phenotype ( $n=43), 17.9 \%$ CPphenotype $(n=27)$ and $53.6 \%(n=81)$ non-ESBL-CP. Distribution of ESBL and CP-phenotypes by source of infection is shown in Fig. S2.

Antimicrobial activity, $\mathrm{MIC}_{50} / \mathrm{MIC}_{90}$ and $\mathrm{MIC}$ range of $\mathrm{C} / \mathrm{T}$ and comparator agents for Enterobacterales broken down by species 
Table 1

Antimicrobial activity of ceftolozane-tazobactam in Enterobacterales broken down by species and source of infection using EUCAST breakpoints.

\begin{tabular}{|c|c|c|c|c|c|c|c|c|}
\hline \multirow[t]{2}{*}{ Organisms } & \multicolumn{2}{|l|}{ IAI } & \multicolumn{2}{|l|}{ LRTI } & \multicolumn{2}{|l|}{ UTI } & \multicolumn{2}{|c|}{ TOTAL } \\
\hline & $\mathrm{n}(\%)$ & ${ }^{\mathrm{a} S}$ & $\mathrm{n}(\%)$ & $S$ & $\mathrm{n}(\%)$ & $S$ & $\mathrm{n}$ & $S$ \\
\hline Enterobacterales & $119(27.9)$ & 88.2 & $94(22.1)$ & 78.7 & $213(50.0)$ & 89.7 & 426 & 86.9 \\
\hline E. coli & $51(29.1)$ & 100.0 & $16(9.1)$ & 100.0 & $108(61.7)$ & 99.1 & 175 & 99.4 \\
\hline ESBL-E. coli & $7(24.1)$ & 100.0 & $3(10.31)$ & 100.0 & $19(65.5)$ & 100 & 29 & 100 \\
\hline Klebsiella spp. & $38(25.2)$ & 73.7 & $46(30.5)$ & 60.9 & $67(44.4)$ & 77.6 & 151 & 71.5 \\
\hline ESBL-Klebsiella spp. & $15(34.9)$ & 66.7 & $9(20.9)$ & 44.4 & $19(44.2)$ & 52.6 & 43 & 55.8 \\
\hline CP-Klebsiella spp. & $6(22.2)$ & 16.7 & $12(44.4)$ & 16.7 & $9(33.3)$ & 44.4 & 27 & 25.9 \\
\hline Enterobacter spp. & $15(40.5)$ & 73.3 & $13(35.1)$ & 84.6 & $9(24.3)$ & 44.4 & 37 & 70.3 \\
\hline Citrobacter spp. & $3(30.0)$ & 100 & $4(40.0)$ & 100 & $3(30.0)$ & 100 & 10 & 100 \\
\hline M. morganii & $2(22.2)$ & 100.0 & $1(11.1)$ & 100 & $6(66.7)$ & 83.3 & 9 & 88.9 \\
\hline Proteus spp. & $5(20.0)$ & 100.0 & $4(16.0)$ & 100.0 & $16(64.0)$ & 100.0 & 25 & 100.0 \\
\hline Serratia spp. & $4(26.7)$ & 100.0 & 7 (46.7) & 100.0 & $4(26.7)$ & 100.0 & 15 & 100.0 \\
\hline Raoultella spp. & $1(33.3)$ & 100 & $2(66.6)$ & 100 & 0 & - & 3 & 100 \\
\hline P. rettgeri & 0 & - & $1(100)$ & 100 & 0 & - & 1 & 100 \\
\hline
\end{tabular}

a Abbreviations: Susceptible (\%) [susceptible (S) plus susceptible, increased exposure (I)]; ESBL, extended-spectrum $\beta$-lactamases; CP, carbapenemases; IAI, intraabdominal infection; LRTI, lower respiratory tract infection; UTI, urinary tract infection; EUCAST, European Committee on Antibiotic Susceptibility Testing.

are shown in Table S2. Data related to species with less than 10 isolates are reported in the text (e.g. Morganella morganii $\mathrm{n}=9$ ). The most potent agent against $E$. coli was C/T [99.4/99.4\% $\mathrm{S}$ EUCAST/CLSI; $\left.\mathrm{MIC}_{50 / 90}, 0.5 / 1 \mathrm{mg} / \mathrm{L}\right]$, along with the carbapenems, MEM (98.9/98.9\% S; $\left.\mathrm{MIC}_{50 / 90}, \leq 0.25 / \leq 0.25 \mathrm{mg} / \mathrm{L}\right)$ and IPM $\left(98.9 / 98.9 \% \mathrm{~S} ; \mathrm{MIC}_{50 / 90}, \leq 0.25 / \leq 0.25 \mathrm{mg} / \mathrm{L}\right)$. Conversely, susceptibility rates against $E$. coli of other $\beta$-lactams were less than $91 \%$ [e.g. AMC $(34.3 / 49.2 \% \mathrm{~S})$ or TZP $(85.2 / 91.4 \% \mathrm{~S})]$. C/T in vitro activity was maintained regardless of the source of infection: IAI, 100\% S; LTRI, $100 \%$ S; and UTI, 99.1\% S (Table 1). In ESBL-E. coli, C/T showed the highest activity $\left(100 / 100 \% \mathrm{~S}, \mathrm{MIC}_{50 / 90}, 1 / 1 \mathrm{mg} / \mathrm{L}\right)$ along with the carbapenems, MEM and IPM (both $100 \% \mathrm{~S}, \mathrm{MIC}_{50 / 90}, \leq 0.25 / \leq 0.25$ $\mathrm{mg} / \mathrm{L})$. Only one $(0.6 \%)$ E. coli isolate was resistant to $\mathrm{C} / \mathrm{T}$. This isolate expressed a $\mathrm{CP}$-phenotype $(\mathrm{MIC}=16 / 4 \mathrm{mg} / \mathrm{L})$ (Fig. 1).

In Klebsiella spp., the more active antimicrobials were AMK (92.8/97.3\% S, EUCAST/CLSI; MIC $\left._{50 / 90} \leq 8 / 16, \mathrm{mg} / \mathrm{L}\right)$ and CST (92.7\%S; $\left.\mathrm{MIC}_{50 / 90} \leq 2 / \leq 2, \mathrm{mg} / \mathrm{L}\right)$. C/T overall susceptibility was $71.5 / 76.8 \%\left(\mathrm{MIC}_{50 / 90}, 1 />64 \mathrm{mg} / \mathrm{L}\right)$. The effect of ESBL and CPphenotypes on $\mathrm{C} / \mathrm{T}$ susceptibility is reflected in Fig. 1. Activity of $\mathrm{C} / \mathrm{T}$ against non-ESBL-CP-Klebsiella spp. isolates $(\mathrm{n}=81)$ was 95.1/98.8\% S. In ESBL-phenotype, the carbapenems were the most active compounds [IPM (100/95.3\% S) and MEM (97.7/95.4\% S)] followed by CST $(97.7 \%$ S). In CP-phenotype, CST (77.8\% S), AMK $(70.4 / 92.6 \% \mathrm{~S})$ and TGC (74.1\% S) presented the highest activity.

Regarding C/T activity by source of infection, in all Klebsiella spp. isolates, activity in IAI, LRTI and UTI was 73.7\%, $60.9 \%$ and $76.6 \% \mathrm{~S}$, respectively. C/T activity against ESBL-phenotype was in all sources $<67.0 \%$ and susceptibility rate ranged from $16.7 \%$ to $44.4 \%$ against CP-phenotype (Table 1). There were 43 (28.8\%) Klebsiella spp. isolates resistant to C/T (EUCAST breakpoints). Distribution by phenotypes was as follows: 4 non-ESBL-CP (3 Klebsiella aerogenes, 1 K. pneumoniae), 19 ESBL-phenotype and 20 CP-phenotype.

Against less common Enterobacterales, C/T activity was excellent in Citrobacter spp. (100/100\% S EUCAST/CLSI; MIC $50 / 90,0.5 / 2$ $\mathrm{mg} / \mathrm{L})$, M. morganii (89.0/89.0\% S), Proteus mirabilis $(100 / 100 \%$, $\left.\mathrm{MIC}_{50 / 90}, 1 / 1 \mathrm{mg} / \mathrm{L}\right)$, Providencia rettgerii (100/100\% S), Raoultella spp. (100/100\% S) and Serratia spp. (100/100\% S, MIC $50 / 90,0.5 / 1$ $\mathrm{mg} / \mathrm{L})$. Nevertheless, C/T showed lower activity in Enterobacter spp. (70.3/73.0\% S, $\mathrm{MIC}_{50 / 90}, 1 / 16 \mathrm{mg} / \mathrm{L}$ ) (Table S2).

\subsection{Molecular characterization of Enterobacterales isolates}

Twenty-nine E. coli isolates expressing ESBL-phenotype were found. Distribution of $\beta$-lactamase genes was as follows: bla $a_{\mathrm{CTX}-\mathrm{M}}$ $(\mathrm{n}=18), b l a_{\mathrm{CTX}-\mathrm{M}+\mathrm{TEM}}(\mathrm{n}=5), b a_{\mathrm{SHV}}(\mathrm{n}=3)$, and $b l a_{\mathrm{TEM}}(\mathrm{n}=1)$. Two isolates with an ESBL-phenotype were not confirmed by con- ventional PCR. Distribution of ESBL-Klebsiella spp. isolates $(\mathrm{n}=43)$ were: $b l a_{\mathrm{CTX}-\mathrm{M}+\mathrm{TEM}}(\mathrm{n}=23), b l a_{\mathrm{CTX}-\mathrm{M}}(\mathrm{n}=6), b l a_{\mathrm{CTX}-\mathrm{M}+\mathrm{SHV}+\mathrm{TEM}}(\mathrm{n}=6)$, bla $_{\mathrm{CTX}-\mathrm{M}+\mathrm{SHV}}(\mathrm{n}=3), \operatorname{bla}_{\mathrm{SHV}}(\mathrm{n}=3)$, bla $_{\mathrm{TEM}}(\mathrm{n}=1)$ and bla $_{\mathrm{SHV}+\mathrm{TEM}}$ $(n=1)$.

Regarding CP genes, in CP-E. coli $(\mathrm{n}=3)$, one bla OXA-48 $_{\text {as }}$ found (two isolates were not confirmed by the molecular assay previously indicated). In CP-Klebsiella spp. $(\mathrm{n}=27)$, bla $_{\mathrm{KPC}}(\mathrm{n}=17)$, bla $a_{\mathrm{OXA}-48}(\mathrm{n}=8)$, and bla $_{\mathrm{VIM}}(\mathrm{n}=1)$ genes were detected. CP production was not confirmed in one isolate. A bla $a_{\mathrm{ESBL}}$ gene was also found in 24 of $27 \mathrm{CP}-$ Klebsiella spp. isolates. Overall, concerning the type of confirmed CP gene in both E. coli and Klebsiella spp. isolates $(\mathrm{n}=27)$, bla $_{\mathrm{KPC}}$ was the most prevalent $(17 / 27,63.0 \%)$, followed by bla $_{\mathrm{OXA}-48}(9 / 27,33.3 \%)$ and bla $\mathrm{VIM}(1 / 27,3.7 \%)$.

In Enterobacter spp. isolates resistant to C/T ( $n=11)$, two ESBLproducers were identified $\left(b l a_{\mathrm{SHV}}\right.$ and $b l a_{\mathrm{CTX}-\mathrm{M}}$ ). No CP genes were detected.

\subsection{Antimicrobial susceptibility of Pseudomonas aeruginosa isolates}

Of 396 clinical isolates, $21.2 \%(n=84)$ were classified as MDR, $23.2 \%(n=92)$ as XDR and $0.8 \%(n=3)$ as PDR, whereas only $17.0 \%$ $(n=67)$ were susceptible to every antipseudomonal agent tested.

Antimicrobial activity, $\mathrm{MIC}_{50} / \mathrm{MIC}_{90}$ and $\mathrm{MIC}$ range of $\mathrm{C} / \mathrm{T}$ and comparator agents tested against $P$. aeruginosa and MDR/XDR phenotypes are shown in Table S3. C/T was the most potent antimicrobial tested against $P$. aeruginosa $\left(94.7 / 95.5 \% \mathrm{~S}\right.$; $\mathrm{MIC}_{50 / 90}$, $1 / 4 \mathrm{mg} / \mathrm{L}$ ), followed by amikacin and tobramycin, applying EUCAST (both $88.9 \% \mathrm{~S}$ ) or colistin and amikacin, with CLSI $(96.2 \% \mathrm{~S}$ and $94.2 \% \mathrm{~S}$, respectively). Rates of resistance within antipseudomonal $\beta$-lactams were as follows: TZP (35.9/24.5\% R, EUCAST/CLSI), CAZ (42.2/30.1\% R), FEP (47.2/23.7\% R) and MEM (24.5/36.1\% R).

$\mathrm{C} / \mathrm{T}$ was also the best agent against MDR and XDR phenotypes (100\% and $79.4 / 82.7 \%$ S, respectively) (Table S3). This activity was retained against isolates resistant to different antipseudomonal agents and combinations (e.g. TZP-CAZ-MEM-R, 70.8\% S), in which $\mathrm{C} / \mathrm{T}$ showed a better activity than comparators like CIP, CST or AMK (Table 2). MIC distributions of C/T against P. aeruginosa show how XDR/PDR phenotypes represent the resistant population (Fig. 1). Of 21 (5.3\%) P. aeruginosa isolates resistant to C/T, 19 were XDR and 2 PDR. The $b l a_{\mathrm{VIM}}$ gene was detected in 3 of 21 (14.3\%) isolates.

The proportion of MDR (19-26\%) and XDR (20-26\%) isolates was similar between types of infection. However, PDR isolates were only found in UTI (Fig. S2). The analysis of susceptibility rates by source of infection also showed $\mathrm{C} / \mathrm{T}$ to be the most potent agent in all of them, and the activity was as follows: $91.3 \% \mathrm{~S}$ in IAI, $98.2 \% \mathrm{~S}$ 


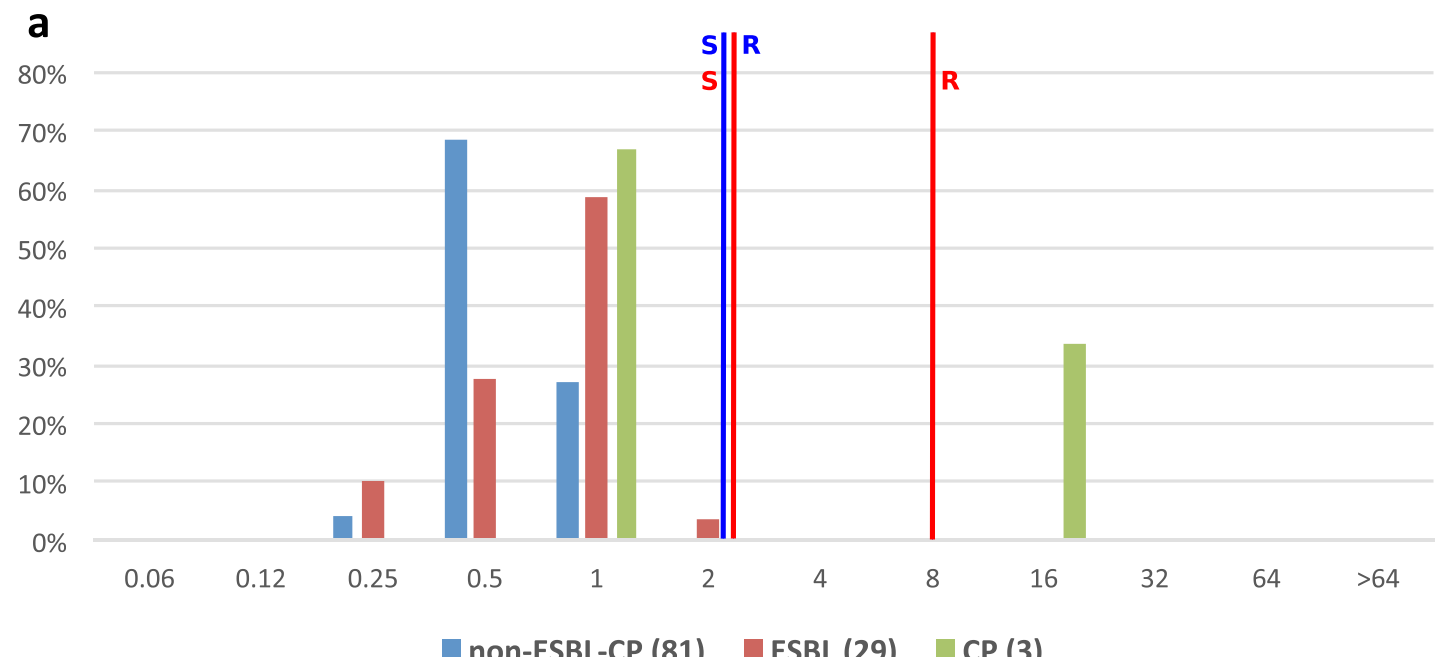

b

$$
\text { non-ESBL-CP (81) } \quad \text { ESBL (29) } \quad \text { CP (3) }
$$

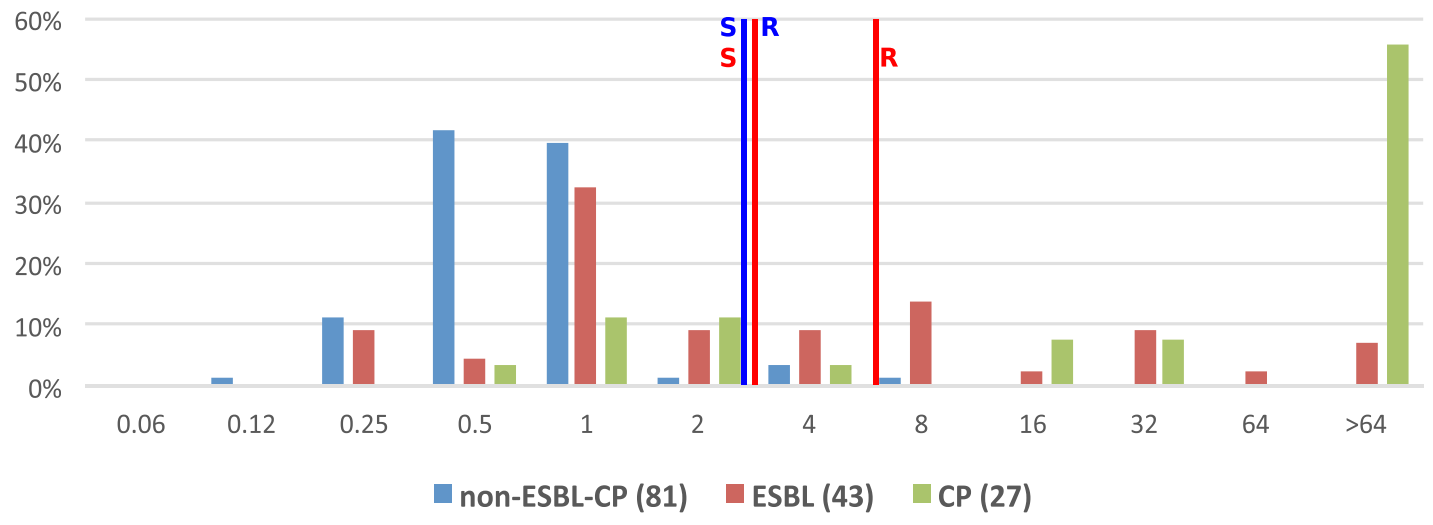

C

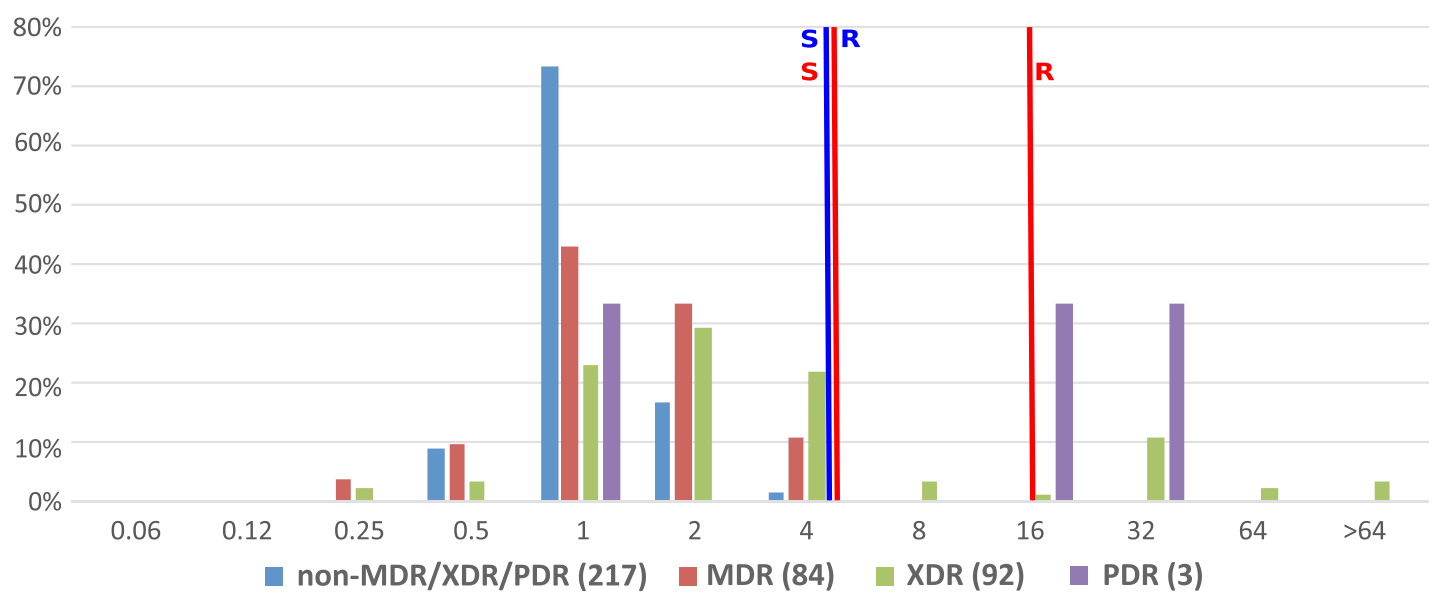

Fig. 1. MIC distribution of C/T in E. coli (a), Klebsiella spp. (b) and P. aeruginosa (c). EUCAST and CLSI breakpoints are displayed with blue and red lines, respectively. Abbreviations: ESBL, extended-spectrum ß-lactamases; CP, carbapenemases; MDR, multidrug-resistant; XDR, extremely-drug resistant; PDR, pan-drug resistant.

in LRTI and $88.9 \% \mathrm{~S}$ in UTI, greater than other antipseudomonal $\beta$-lactams [TZP $(\leq 76.3 \%)$, CAZ $(\leq 64.4 \%)$ and MEM $(\leq 77.8 \%)$ ]. Regarding other antibiotics, susceptibility rates were CST $(\leq 81.3 \%)$, CIP $(\leq 63.8 \%)$ and AMK ( $\leq 93.8 \%)$ (Table 2$)$.

\subsection{Antimicrobial susceptibility according to different participating hospitals}

Overall activity of C/T in Enterobacterales by participant hospital was diverse (from $67.6 \% \mathrm{~S}$ to $96.4 \% \mathrm{~S}$ ). There was no difference regarding C/T activity between E. coli isolates (in 10 of 11 sites, $100 \%$
S), whereas in Klebsiella spp. isolates, susceptibility to C/T ranged from $44.4 \%$ to $100 \%$. This was mostly because of a diverse proportion of ESBL-Klebsiella spp. isolates (0-65.2\%, and only one site was without ESBL) and CP-phenotypes (0-44.4\%, and three sites without CP) (Table S4 and Fig. S1).

In $P$. aeruginosa isolates, $\mathrm{C} / \mathrm{T}$ activity differed slightly between hospitals ( $87.1 \% \mathrm{~S}$ to $100 \% \mathrm{~S}$ ) and was $100 \% \mathrm{~S}$ in 4 of 11 hospitals. MDR phenotype was not found in only one center, and the proportion of MDR in the others was $14.3 \%$ to $33.3 \%$. Regarding XDR, this phenotype was not detected in one hospital, and ranged from $18.5 \%$ to $35.5 \%$ in the other centers (Table S5 and Fig. S1). 
Table 2

Susceptibility $^{\mathrm{a}}(\%)$ of ceftolozane-tazobactam and comparators by resistance phenotypes and source of infection in P. aeruginosa according to EUCAST breakpoints.

\begin{tabular}{|c|c|c|c|c|c|c|c|}
\hline & $\mathrm{C} / \mathrm{T}$ & TZP & CAZ & MEM & CST & CIP & AMK \\
\hline All P. aeruginosa (396) & 94.7 & 64.1 & 57.8 & 75.5 & 78.3 & 62.9 & 88.9 \\
\hline $\mathrm{TZP}^{\mathrm{b}}(142)$ & 85.2 & - & 10.6 & 46.5 & 75.4 & 39.4 & 78.2 \\
\hline CAZ-R (167) & 87.4 & 24.0 & - & 50.9 & 74.3 & 46.7 & 80.2 \\
\hline MEM-R (97) & 78.4 & 21.7 & 15.5 & - & 72.2 & 23.7 & 67.0 \\
\hline TZP-CAZ-R (127) & 83.5 & - & - & 43.3 & 74.8 & 35.4 & 76.4 \\
\hline TZP-CAZ-MEM-R (72) & 70.8 & - & - & - & 73.6 & 16.7 & 61.1 \\
\hline MDR (84) & 100.0 & 51.7 & 41.4 & 79.3 & 70.1 & 57.1 & 94.0 \\
\hline XDR (92) & 79.4 & 7.6 & 9.8 & 22.8 & 68.5 & 12.0 & 65.2 \\
\hline IAI- $P$. aeruginosa (80) & 91.3 & 76.3 & 57.5 & 72.5 & 81.3 & 63.8 & 83.8 \\
\hline LTRI-P. aeruginosa (226) & 98.2 & 59.7 & 55.3 & 75.7 & 79.7 & 63.3 & 93.8 \\
\hline UTI-P. aeruginosa (90) & 88.9 & 64.4 & 64.4 & 77.8 & 72.2 & 61.1 & 81.1 \\
\hline
\end{tabular}

Abbreviations: C/T, ceftolozane-tazobactam; TZP, piperacillin-tazobactam; CAZ, ceftazidime; MEM, meropenem; CST, colistin; CIP, ciprofloxacin; AMK, amikacin; MDR, multidrug-resistant; XDR, extremely-drug resistant; IAI, intraabdominal infection; LRTI, lower respiratory tract infection; UTI, urinary tract infection; EUCAST, European Committee on Antibiotic Susceptibility Testing.

a Susceptible [susceptible $(\mathrm{S})$ plus susceptible, increased exposure (I)]

b Resistant

\section{Discussion}

To the best of our knowledge, this is the first surveillance study in Portugal focusing on antimicrobial susceptibility profiles in isolates causing infections in ICUs. This study provides information about distribution of ESBL-CP-phenotypes in Enterobacterales and MDR/XDR/PDR phenotypes in P. aeruginosa in this country.

Results in Enterobacterales reaffirm that prevalence of CPproducing Enterobacterales (CPE) is increasing in Portugal [16]. Data from EARS-Net showed levels of carbapenem resistance no greater than $0.3 \%$ or $8.6 \%$ in E. coli and K. pneumoniae, respectively [3]. In contrast, this study showed higher rates in E. coli (up to $1.1 \%$ or 2.6\% R, applying EUCAST or CLSI, respectively) and Klebsiella spp. (up to $17.2 \%$ or $19.9 \%$ R, EUCAST/CLSI). Only K. pneumoniae isolates rates were up to $20.8 \% \mathrm{R}$ in EUCAST and CLSI. Previous studies of $\mathrm{CP}$ distribution in Portugal showed a dominance of Klebsiella pneumoniae carbapenemase (KPC; >85\%) within confirmed CPE with the absence of OXA-48 [4,5]. This enzyme was not detected in Portugal until 2013 [17]. Our survey indicated the relevant prevalence of OXA-48 (33.3\%) in CPE in a setting where KPC-enzymes (63.0\%) continue to dominate.

$\mathrm{C} / \mathrm{T}$ was the most active antimicrobial tested along with carbapenems against E. coli and other less represented Enterobacterales species. This is consistent with other studies performed in other countries [18-20]. Indeed, C/T was 100/100\% S (EUCAST/CLSI) against ESBL-E. coli. The activity against Klebsiella spp. isolates was more modest $(71.5 / 76.8 \% \mathrm{~S})$ and also consistent with earlier studies $[18,21]$. A high proportion of ESBL and CP-phenotypes was found in our survey in Klebsiella spp. isolates, $28.5 \%$ and $17.9 \%$, respectively. Nevertheless, C/T activity against non-ESBL-non-CP Klebsiella spp. was $95.1 / 98.8 \% \mathrm{~S}$. Due to a diverse proportion of ESBL and CP-phenotypes (Fig. S1), there were differences in C/T activity by source of infection (e.g. C/T susceptibility in Klebsiella spp. was 60.9/73.7/77.6\% S in LRTI, IAI and UTI, respectively). Previous studies have reported less activity of C/T in Enterobacter spp., with ESBL-production or AmpC-overproduction possible reasons for this observation [22].

On the other hand, high resistant rates were found in $P$. aeruginosa isolates from ICU patients in this survey. Resistance to antipseudomonal $\beta$-lactams ( $>24.5 \% \mathrm{R}$ in TZP, CAZ and MEM) was considerably above the rates described in the last EARS-Net report [3]. In fact, no antimicrobial expressed a susceptibility rate $>90 \%$ $\mathrm{S}$ (EUCAST breakpoint) against $P$. aeruginosa, except for $\mathrm{C} / \mathrm{T}$. Despite the high rates of resistance in $P$. aeruginosa isolates in this survey, C/T was the best antimicrobial tested $(94.7 / 95.5 \% \mathrm{~S}$, EUCAST/CLSI), followed by AMK and TOB. This susceptibility rate was maintained against MDR (100\% S) and XDR (79.4/82.7\% S) isolates, and against different antipseudomonal resistant phenotypes. These results agree with recent European surveys, with C/T susceptibility rates up to $90 \%[19,21,22]$. C/T was also superior to every comparator agent analysed by source of infection, consolidating its position as a treatment for $P$. aeruginosa-causing infections. In nearly $15 \%$ of the $P$. aeruginosa isolates, resistance to $\mathrm{C} / \mathrm{T}$ was due to the presence of a metallo-beta-lactamase. In the remaining C/T-resistant isolates, other mechanisms might be involved, such as Guiana extendedspectrum (GES) enzymes or multiple mutations leading to overexpression and structural modifications of AmpC [23-25]. The differences in C/T activity by participant hospital (susceptibility rates in Enterobacterales from $67.6 \%$ to $96.4 \%$ or $87.1 \%$ to $100 \%$ in P. aeruginosa) and by source of infection reflect the importance of surveillance studies to enhance knowledge of local epidemiology and impact local guidelines.

In conclusion, $\mathrm{C} / \mathrm{T}$ was the most potent agent tested against $P$. aeruginosa recovered from ICU patients; this activity was maintained regardless of a resistant phenotype. In Enterobacterales, C/T exhibited good overall activity against $E$. coli, although it might be affected by local epidemiology in other species, such as Klebsiella spp. and Enterobacter spp. These microbiological results reinforce $\mathrm{C} / \mathrm{T}$ as a therapeutic option in ICU patients with UTI, IAI or LRTI due to P. aeruginosa or Enterobacterales isolates, but not for CP producers. Furthermore, this study provides information about molecular epidemiology of CPE in Portugal, particularly the presence of OXA-48 in a setting where KPC enzymes are the dominant CP.

\section{Acknowledgments}

The STEP Study Group includes the following members: José Melo-Cristino, Serviço de Microbiologia Centro Hospitalar Lisboa Norte, Lisboa, Portugal; Margarida F. Pinto, Cristina Marcelo, Helena Peres, Isabel Lourenço, Isabel Peres, João Marques, Odete Chantre, Teresa Pina, Laboratório de Microbiologia, Serviço de Patologia Clínica, Centro Hospitalar Universitário Lisboa Central, Lisboa, Portugal; Elsa Gonçalves, Cristina Toscano. Laboratório de Microbiologia Clínica Centro Hospitalar de Lisboa Ocidental, Lisboa, Portugal; Valquíria Alves, Serviço de Microbiologia, Unidade Local de Saúde de Matosinhos, Matosinhos, Portugal; Manuela Ribeiro, Eliana Costa, Ana Raquel Vieira, Serviço Patologia Clínica, Centro Hospitalar Universitário São João, Porto, Portugal; Sónia Ferreira, Raquel Diaz, Elmano Ramalheira, Serviço Patologia Clínica, Hospital Infante Dom Pedro, Aveiro, Portugal; Sandra Schäfer, Luísa Tancredo, Luísa Sancho, Serviço de Patologia Clínica, Hospital Prof. Dr. Fernando Fonseca, Amadora, Portugal; Ana Rodrigues, José Diogo, Serviço de Microbiologia, Hospital Garcia de Orta, Almada, Portugal; Rui Ferreira, Serviço de Patologia Clínica - Microbiologia 
- CHUA - Unidade de Portimão, Portugal; Helena Ramos, Tânia Silva, Daniela Silva, Serviço de Microbiologia, Centro Hospitalar Universitário do Porto, Porto, Portugal; Catarina Chaves, Carolina Queiroz, Altair Nabiev, Serviço de Microbiologia, Centro Hospitalar Universitário de Coimbra, Coimbra, Portugal; Leonor Pássaro, Laura Paixao, João Romano, Carolina Moura. MSD Portugal, Paço de Arcos, Portugal. María García del Castillo, Sergio García-Fernández, Marta Hernández-García and Rafael Cantón, Hospital Ramón y Cajal, Madrid, Spain.

\section{Declarations}

Funding: The study was funded by MSD Portugal (protocol VP6918) and supported by Plan Nacional de I+D+i 2013-2016 and Instituto de Salud Carlos III, Subdirección General de Redes y Centros de Investigación Cooperativa, Ministerio de Economía, Industria y Competitividad, Spanish Network for Research in Infectious Diseases (RD16/0016/0011) cofinanced by European Development Regional Fund "A way to achieve Europe" (ERDF), Operative program Intelligent Growth 2014-2020. SG-F is supported by a research contract from Instituto de Salud Carlos III, Spain [Rio Hortega program, ref. CM17/00033].

Competing Interests: RC has participated in educational programs organized by MSD and Pfizer. Dra. Margarida F. Pinto had a travel grant for ECCMID-2019 from MSD Portugal. Leonor Pássaro and Laura Paixão are both MSD Portugal employees and/or may hold stock options in Merck \& Co., Inc., Kenilworth, NJ, USA. The other authors have no conflict of interests.

\section{Ethical Approval: Not required.}

\section{Supplementary materials}

Supplementary material associated with this article can be found, in the online version, at doi:10.1016/j.ijantimicag.2020. 105887.

\section{References}

[1] Castanheira M, Deshpande LM, Mendes RE, Canton R, Sader HS, Jones RN. Variations in the occurrence of resistance phenotypes and carbapenemase genes among Enterobacteriaceae isolates in 20 Years of the SENTRY Antimicrobial Surveillance Program. Open Forum Infect Dis 2019;6:S23-33. doi:10.1093/ofid/ ofy347

[2] Shortridge D, Gales AC, Streit JM, Huband MD, Tsakris A, Jones RN. Geographic and temporal patterns of antimicrobial resistance in Pseudomonas aeruginosa over 20 years from the SENTRY Antimicrobial Surveillance Program, 1997-2016. Open Forum Infect Dis 2019;6:S63-8. doi:10.1093/ofid/ofy343.

[3] European Centre for Disease Prevention and Control. Surveillance of antimicrobial resistance in Europe 2017. Annual Report of the European Antimicrobial Resistance Surveillance Network (EARS-Net). Stockholm: ECDC. 2018.

[4] Manageiro V, Romão R, Moura IB, Sampaio DA, Vieira L, Ferreira E, et al. Molecular epidemiology and risk factors of carbapenemase-producing Enterobacteriaceae isolates in Portuguese Hospitals: results from European Survey on carbapenemase-producing Enterobacteriaceae (EuSCAPE). Front Microbiol 2018;9:2834. doi:10.3389/fmicb.2018.02834.

[5] Manageiro V, Ferreira E, Almeida J, Barbosa S, Simões CAntibiotic Resistance Surveillance Program in Portugal (ARSIP). Predominance of KPC-3 in a Survey for Carbapenemase-Producing Enterobacteriaceae in Portugal. Antimicrob Agents Chemother 2015;59:3588-92. doi:10.1128/AAC.05065-14.

[6] van Duin D, Bonomo RA. Ceftazidime/avibactam and ceftolozane/tazobactam: second-generation $\beta$-lactam $/ \beta$-lactamase inhibitor combinations. Clin Infect Dis 2016;63:234-41. doi:10.1093/cid/ciw243.
[7] Moya B, Zamorano L, Juan C, Pérez JL, Ge Y, Oliver A. Activity of a new cephalosporin, CXA-101 (FR264205), against beta-lactam-resistant Pseudomonas aeruginosa mutants selected in vitro and after antipseudomonal treatment of intensive care unit patients. Antimicrob Agents Chemother 2010;54:1213-17. doi:10.1128/AAC.01104-09.

[8] Castanheira $\mathrm{M}$, Rhomberg PR, Flamm RK, Jones RN. Effect of the $\beta$ lactamase inhibitor vaborbactam combined with meropenem against serine carbapenemase-producing Enterobacteriaceae. Antimicrob Agents Chemother 2016;60:5454-8. doi:10.1128/AAC.00711-16.

[9] https://www.fda.gov/news-events/press-announcements/fda-approves-newtreatment-hospital-acquired-and-ventilator-associated-bacterial-pneumonia n.d.

[10] CLSI. Methods for Dilution Antimicrobial Susceptibility Tests for Bacteria that Grow Aerobically. 11th ed. Wayne, PA: Clinical and Laboratory Standards Institute; 2018. CLSI standard M07n.d.

[11] The European Committee on Antimicrobial Susceptibility Testing. Breakpoint tables for interpretation of MICs and zone diameters. Version 10.0. 2020.

[12] CLSI. Performance standards for antimicrobial susceptibility testing. 28th ed. Wayne, PA: Clinical and Laboratory Standards Institute; 2018. CLSI supplement M100n.d.

[13] Livermore DM. beta-Lactamases in laboratory and clinical resistance. Clin Microbiol Rev 1995;8:557-84.

[14] Magiorakos A-P, Srinivasan A, Carey RB, Carmeli Y, Falagas ME, Giske CG, et al. Multidrug-resistant, extensively drug-resistant and pan-drug-resistant bacteria: an international expert proposal for interim standard definitions for acquired resistance. Clin Microbiol Infect 2012;18:268-81. doi:10.1111/j. 1469-0691.2011.03570.x

[15] Ruiz-Garbajosa P, Hernández-García M, Beatobe L, Tato M, Méndez MI, Grandal M, et al. A single-day point-prevalence study of faecal carriers in longterm care hospitals in Madrid (Spain) depicts a complex clonal and polyclonal dissemination of carbapenemase-producing Enterobacteriaceae. J Antimicrob Chemother 2016;71:348-52. doi:10.1093/jac/dkv355.

[16] Albiger B, Glasner C, Struelens MJ, Grundmann H, Monnet DLEuropean Survey of Carbapenemase-Producing Enterobacteriaceae (EuSCAPE) working group. Carbapenemase-producing Enterobacteriaceae in Europe: assessment by national experts from 38 countries, May 2015. Euro Surveill 2015;20. doi:10.2807/ 1560-7917.ES.2015.20.45.30062.

[17] Manageiro V, Ferreira E, Pinto M, Caniça M. First description of OXA-48 carbapenemase harbored by Escherichia coli and Enterobacter cloacae from a single patient in Portugal. Antimicrob Agents Chemother 2014;58:7613-14. doi:10.1128/AAC.02961-14.

[18] Pfaller MA, Bassetti M, Duncan LR, Castanheira M. Ceftolozane/tazobactam activity against drug-resistant Enterobacteriaceae and Pseudomonas aeruginosa causing urinary tract and intraabdominal infections in Europe: report from an antimicrobial surveillance programme (2012-15). J Antimicrob Chemother 2017;72:1386-95. doi:10.1093/jac/dkx009.

[19] Castanheira M, Duncan LR, Mendes RE, Sader HS, Shortridge D. Activity of ceftolozane-tazobactam against Pseudomonas aeruginosa and Enterobacteriaceae isolates collected from respiratory tract specimens of hospitalized patients in the United States during 2013 to 2015. Antimicrob Agents Chemother 2017;62 e02125-17. doi:10.1128/AAC.02125-17.

[20] García-Fernández S, García-Castillo M, Bou G, Calvo J, Cercenado E, Delgado M et al. Activity of ceftolozane/tazobactam against Pseudomonas aeruginosa and Enterobacterales isolates recovered from intensive care unit patients in Spain: The SUPERIOR multicentre study. Int J Antimicrob Agents 2019;53:682-8. doi:10.1016/j.ijantimicag.2019.02.004.

[21] Bouxom H, Fournier D, Bouiller K, Hocquet D, Bertrand X. Which noncarbapenem antibiotics are active against extended-spectrum $\beta$-lactamaseproducing Enterobacteriaceae? Int J Antimicrob Agents 2018;52:100-3. doi:10. 1016/j.ijantimicag.2018.03.014.

[22] Robin F, Auzou M, Bonnet R, Lebreuilly R, Isnard C, Cattoir V, et al. In vitro activity of ceftolozane-tazobactam against Enterobacter cloacae complex clinical isolates with different $\beta$-lactam resistance phenotypes. Antimicrob Agents Chemother 2018;62(9). doi:10.1128/AAC.00675-18.

[23] Del Barrio-Tofiño E, Zamorano L, Cortes-Lara S, López-Causapé C, SánchezDiener I, Cabot G, et al. Spanish nationwide survey on Pseudomonas aeruginosa antimicrobial resistance mechanisms and epidemiology. J Antimicrob Chemother 2019;74(7):1825-35. doi:10.1093/jac/dkz147.

[24] Giani T, Arena F, Pollini S, Di Pilato V, D’Andrea MM, Henrici De Angelis L, et al. Italian nationwide survey on Pseudomonas aeruginosa from invasive infections: activity of ceftolozane/tazobactam and comparators, and molecular epidemiology of carbapenemase producers. J Antimicrob Chemother 2018;73:664-71. doi:10.1093/jac/dkx453.

[25] Cabot G, Bruchmann S, Mulet X, Zamorano L, Moyà B, Juan C, et al. Pseudomonas aeruginosa ceftolozane-tazobactam resistance development requires multiple mutations leading to overexpression and structural modification of AmpC. Antimicrob Agents Chemother 2014;58:3091-9. doi:10.1128/AAC. 02462-13. 